\title{
Preliminary Investigation of the Integration of Engineering into K-12 Education
}

\author{
Mary Spencer \\ M.Sc. Candidate \\ Queen's University Kingston \\ spencerm@appsci.queensu.ca
}

\author{
David S. Strong, P.Eng. \\ Professor, NSERC Design Chair \\ Queen's University Kingston \\ strongd@queensu.ca
}

\begin{abstract}
There has been a general decline in the number of students applying for engineering programs among Western nation's universities over the last decade. For this society to continue advancing, particularly with the growing emphasis on sustainable practices, it is necessary to reverse this trend and grow the number of students who choose engineering as a profession. It is generally accepted that kindergarten through high school (K-12) education has significant influence on a student's choice of university programs. It is proposed that initiatives be developed to foster interest in the profession of engineering long before students make post-secondary education choices. Potential mechanisms to fulfill this need could include direct student curricular programs, development for teachers, and outreach opportunities for students. As a first step, this paper discusses an initial investigation into current $K-12$ approaches to increasing awareness of and interest in engineering, as well as the effectiveness of the approaches.
\end{abstract}

\section{Introduction}

Over the past 20 years the number of students entering engineering programs has been declining [1]. Currently, the United States graduates about 75,000 engineers each year, Canada graduates around 11,000, and China surpasses both at 350,000 per year [2]. This decline in total students entering this field of study has and will adversely affect society. The result is a shortage of skilled professionals available in the workplace.

Historically, engineering occupations have grown faster than other occupations [3]. In addition to the rapid increase in jobs available, the number of degrees being earned in these fields does not match the demand for employees. Twenty-six percent of employees in engineering are over the age of 50; in the coming decade society will be losing a quarter of its skilled workers [3].

To meet the growing demand for graduate engineers, change must occur which will lead to an increase in interested students to these fields. While this change can be approached in a variety of different ways, this report will focus on change in teacher training, teacher and student programs, and outreach activities.

\section{Teachers}

Teachers play an integral role influencing the way engineering is viewed by K-12 students, and, therefore, are a necessary part of any solution to the existing decline. Teachers are able to guide the way in which students perceive their own abilities. If a teacher believes that a student has the ability to become an engineer they may encourage that student to seek out relevant math and science course material. If, however, the opposite is true, the teacher may encourage the student to pursue other interests. The perception by the teacher of a student's ability may influence the teacher's guidance of the academic direction of that student [4].

Math and science instructional positions are traditionally the hardest to fill with qualified teachers. The reason for this is that many people with degrees in math and science choose to enter industry as opposed to teaching, resulting in a smaller pool of qualified applicants. This subsequently leads to less qualified individuals being hired for math and science teaching positions [5]. As a result, it can be suggested that teachers have difficulty encouraging their students to become engineers because they do not have an understanding of what an engineering career encompasses [4]. Training will give teachers the ability to convey meaningful and accurate information about the engineering profession to their students.

It is important that teachers understand the engineering profession, particularly its breadth of 
opportunities and topics, and the excitement and challenges of being creative and innovative. The rewards of a professional engineering career should be conveyed clearly to all K-12 students. Another key topic for teachers to understand about engineering is the design process. The engineering design process is expressed differently in various publications, however, a generally accepted outline, as suggested by the "Engineering the Future" textbook defines the basic process as follows: define the problem, research the problem, develop possible solutions, choose the best solution, create a drawing or prototype, test and evaluate, communicate and iterate as required [6].

Approaches to the design process vary greatly between the methods used by K-12 students compared to university students. K-12 design projects are generally more craft oriented, and based on trial and error instead of the design process. University students should ideally use theoretical tools and scientific information to decide on an appropriate design solution. In order to convey the difference in these methods, enabling K-12 students to start to use a true engineering design process, teacher training must improve [7].

\subsection{Programs for Teachers Only}

In the United States, various programs have been initiated for current teachers to expand their knowledge about engineering concepts. These courses or programs are offered during the school year on professional development (P.D.) days or during the summer when teachers have vacation. Aside from the state of Massachusetts, engineering is not currently part of K-12 curriculums [8]. Since engineering is not included in the majority of curriculums, it has become the responsibility of the teachers at the local level to integrate engineering awareness and concepts into the classroom. P.D. programs are designed to educate teachers about engineering. Some example programs are outlined below.

The National Center for Engineering and Technology (NCETE) is dedicated to introducing and emphasizing engineering ideals in the K-12 curriculum. There are five universities that participate in NCETE's teacher P.D. days: North Carolina A\&T University; Brigham Young University; California State University, Los Angeles; Illinois State University; and the University of Wisconsin-Stout. These universities, in conjunction with NCETE, strive to provide programs for teachers to assist them in learning about engineering concepts.

The NCETE P.D. day programs started in 2005. The main goals of the professional development days are [9]:
- Develop teachers' instructional decision making to focus on the analytical nature of design and problem solving needed to deliver technological and engineering concepts.

- Facilitate teacher initiated change in program design, and other areas related to learning.

- Develop teachers' capabilities as learners so they assume leadership for professional development days and thus recruit and train other teachers [10].

In order to emphasize the open ended problems that are encountered by engineers, teachers were not provided with set lesson plans that would result in the same outcome each time they were conducted. The training revolved around discussions on what engineering is, design challenges, and in-depth learning in math and science. It was found in many of the programs that teachers needed assistance implementing their new knowledge in the classroom. In many cases, the need for assistance in implementation was due to teachers being fearful of bringing something new into the classroom. This fear was relieved with additional instruction and resources from the universities [9]. NCETE programs have been successful in conveying the message of what engineering is to teachers and subsequently transmitting the message into classrooms.

Project Pathways, based in Arizona, is focused on improving teacher P.D. training in areas pertaining to science, technology, engineering, and math (collectively referred to as STEM). One basis for improvement in teacher training is to have teachers spend more time with other teachers, not students. Although counter intuitive, the National Partnership for Excellence and Accountability in Teaching remarks that "teachers are more likely to change when they feel involved and supported in a collegial community of learners" [11]. This implies that teachers who introduce engineering skills into their classroom activities on their own will begin to feel isolated in their practices. This isolation can lead to stunted growth in the delivery and application of engineering education to students. The targets of Project Pathways are [11]:

- Shift teachers' practice to inquiry and project based methods.

- Increase teachers' ability to reflect on, monitor, and adjust classroom practices.

- Deepen teachers' understanding of mathematics, their knowledge of mathematical connections, and their ability to use mathematics in science and engineering design applications.

- Increase secondary student achievement in math and science. 
- Close the achievement gap of minority secondary students in each school.

- Improve students' problem solving, scientific inquiry, and engineering design strategies (STEM) and confidence in their STEM abilities.

- Measure shifts in teacher practice and student conceptual learning in Arizona State University's (ASU) introductory pre calculus, physics, engineering, and other STEM courses.

- Improve success rate in ASU introductory pre calculus, calculus, physics, and biology courses.

Primary Engineering (PE) is an organization based in the United Kingdom (UK) "dedicated to furthering design technology in primary schools" [12]. This organization oversees a variety of programs run by universities throughout the UK. PE offers several two day courses to teachers on engineering topics, such as Structures and Mechanisms with Basic Electrics [12]. PE is responsible for instructing secondary school teachers on the skills needed to convey engineering principles to others. The secondary school teachers, after completion of their training, coordinate courses for primary school teachers to inform them of the many opportunities in the engineering field and how to incorporate engineering into their daily classes [12]. This seems like an ideal set up to reach the highest number of teachers and students in an efficient manner.

The main purpose of these programs is to transport knowledge of engineering to teachers. The conveyance of engineering methodologies benefits the teachers in two ways; first, teachers are able to grasp the generalities of engineering; second, teachers can pass this knowledge on to their students. Once the teachers are able to grasp engineering concepts, it becomes easier for them to convey it to their students. This enables teachers to approach engineering in a positive way and subsequently can encourage their students to explore engineering.

\subsection{Teacher and Student Programs}

A number of programs exist to assist teachers in presenting engineering material to their students. In these programs, the classroom teachers are usually given an introduction to engineering before demonstrating or conducting a class, that has engineering integrated into the lesson. Many of the programs include involvement from local universities. Graduate and undergraduate students from the universities enter the classrooms and assist the teachers as they conduct activities to engage students in an inclusive teaching environment.

Engineering Our Future New Jersey (EOFNJ) is a joint effort between Stevens Institute of Technology's Center for Innovation in Engineering and Science Education (CIESE), the New Jersey Department of Education, the Museum of Science, Boston's National Centre for Technological Literacy, and other partners to bring engineering to students in $\mathrm{K}-12$. EOFNJ began as a pilot study to introduce engineering into the school system; currently it is being implemented statewide [13]. EOFNJ divided the grades K-12 into elementary, middle, and high school aged projects. Teachers participating in the program were expected to complete the following tasks:

- Attend a two day teacher workshop.

- Deliver the selected modules that were presented at the workshop between January and June.

- Receive CIESE staff into classrooms to support and observe implementation.

- Administer pre and post surveys to students.

- Participate in a focus group about the effectiveness of the program.

- Complete surveys regarding the implementation [13].

If all tasks were completed, teachers received $\$ 300$. The modules that were implemented in the classroom were centered on a design project that suited the student's grade level. The program results concluded that a positive impact on student learning at all levels was achieved. There is now a correlation between the engineering curricula and the New Jersey Core Curriculum Content Standards [13].

The Technology and Engineering to Advance Math and Science (TEAMS) program began at the University of Colorado's College of Engineering and Applied Science's Integrated Teaching and Learning (ITL) program. This program, similar to others, pairs undergraduate and graduate students with preuniversity classrooms to give guidance on engineering. One main focus of the program is to increase the enrollment into Centaurus High School's PreEngineering Program. The program also aims to attract minorities in engineering such as females, low income youth, and first generation college students [14].

To accomplish these goals, the program has university students enter grade 3-12 classrooms each week to conduct lessons with the class. The lessons are based on engineering design and tie into the current curriculum in which the students are working [14]. 
Student Teacher Outreach Mentorship Program (STOMP) began in 2001 at Tufts University. The purpose of the program is to engage undergraduate and graduate students in the teaching of engineering concepts to K-12 participants. The university participants of the program are assigned to a classroom within a school for the entire semester. The university participants plan and carry out various activities with groups of K-12 students, most of the activities occurring during the K-12 students' normal school day. The activities that the university participants carry out are generally related to current topics being covered in the curriculum. The STOMP program has been expanded to reach other communities outside of the Tufts area by involving other universities and participants from the engineering industry. Approximately $360 \quad$ K-12 students were impacted by this program the 2007-2008 school year [15].

EngQuest, an Australian program supported by the Government of Australia and Engineers Australia since 1996, is an online program offered to all teachers and students within the country. Students and teachers $\log$ on to the EngQuest interactive website to learn about engineering. The student portion of the website involves games, a blog, a forum, and project outlines. The teacher portion of the site provides teachers with more background information on the projects on which their students are working and notifies them if their students ask a question on the site [16].

Students, depending on their school level, are given tasks to investigate current engineering devices to obtain knowledge that is used in a project to emphasize engineering design. Topics in 2008 were: simple machines, engineering in the community, and build it. Teachers are provided with additional material to emphasize the design aspect as well as relating the material to the current curriculum. Engineers Australia's members enter the classroom to assist teachers in implementing the engineering program. On average, 5000 students participate in this program each year [16].

These programs exemplify the symbiotic partnership that can occur between K-12 schools and universities. The education and support that the universities and industry provide to the K-12 teachers and students then benefits them in the supply of capable students to their program or industry. Programs similar to these should continue to be developed and improved.

\section{Outreach}

In addition to improving teachers' ability to discuss and simplified applications of the engineering profession with their students, there is also a significant opportunity for students to be encouraged to explore engineering through other means outside the classroom. These extra-curricular programs, typically referred to as "outreach", are usually offered to local communities by engineering faculties within universities, sometimes in conjunction with industry. The primary goal of all of these activities is to increase the pool of students who are capable and interested in taking engineering at a university level [17].

\subsection{Women and Minority Outreach}

Various activities take place to involve women and minority students in engineering outside of school. These programs range from one day events to weekly or monthly activities run by universities or industry. The main premise of these programs is to provide a time and location for these individuals to learn more about the engineering process.

The percentage of women graduating with bachelor's degrees in engineering has hovered around $20 \%$ for several years [18]. The increase of both women and minorities in engineering is stagnant [19]. As said by Dr. Wulf, President of the National Academy of Engineering, "Every time an engineering problem is approached with a pale, male design team, it may be difficult to find the best solution, understand the design options, or know how to evaluate the constraints." It is believed that an increase in the numbers of women and minorities in engineering would benefit society as a whole because of the different perspectives and experiences they would bring to the profession [20].

To advance the number of women in engineering, many initiatives have been created, primarily through universities. Some of these programs are Hi-GEAR, Introduce a Girl to Engineering Day, and Educating Girls for Engineering (EDGE).

Hi-GEAR is a program run by the University of Utah that began in 2001. Thirty five female students are selected each year to participate in the 5 day camp [21]. Through the week, the girls learn about different types of engineering and the engineering design process through hands on, inquiry based activities led by female mentors. EDGE is run by Purdue University and is very similar in character to HiGEAR [22]. 
Introduce a Girl to Engineering Day (Girl Day) is a nationwide day during National Engineering Week. During this day, girls are brought to engineering offices or universities to learn about the profession. Many of the days involve the girls completing hands on activities to discover what engineering is. As part of Girl Day, the Engineer Your Life website was launched as a resource for girls, teachers, and parents to learn about engineering [23].

Programs for minorities are often similar in nature to those which promote women in engineering. Often, programs are designed to accommodate visible minorities and women because both are demographically underrepresented in the engineering profession. Explorations in Engineering, offered by the Michigan Technology Institute, allows minorities and women to experience engineering through a weeklong camp during the summer. Within the camp, participants are led specifically by minorities and women in order to provide concrete examples of people with similar backgrounds who have become engineers [24]. These role models offer a positive outlook on engineering for the participants because participants can see themselves in their shoes. The camps also provide participants with firsthand experience on engineering design projects. Mississippi State University's Bagley College of Engineering offers a similar program for minorities to learn about engineering through hands on experience and role models [25].

The examples presented here are just a handful of the programs that are available across the United States for this target group to become informed on the opportunities in engineering. These programs provide students the opportunity to have hands on experience with engineering and to ask questions and voice concerns they may not feel comfortable doing otherwise with their parents or teachers. In addition, it creates role models for participants to look to for guidance.

\section{The Canadian Perspective}

According to the literature, there are no visibly active teacher "engineering training" programs in Canada. Unless education graduates have an engineering degree, have taken an engineering elective, have been taught by their curriculum professor, or encounter engineering later in their career, they will graduate and continue to teach without knowledge of engineering [26]. This is a critical oversight that should be corrected.

\subsection{The Queen's Experience}

Currently, few programs involving teachers and students are in place at Queens University (QU). Due to the lack of formal and funded support for these programs they are only run occasionally and voluntarily. However, like many Canadian universities, there are several outreach programs that are consistently run from year to year at QU. The main premise of these programs in to engage K-12 students in engineering activities.

\subsection{Outreach Activities}

Outreach programs at QU, and undoubtedly at other institutions, fluctuate with budgets and administrative interests. Two main programs are run by the faculty at QU, and in addition the QU Engineering Society runs a camp during the summer. Comparable programs can be found at other universities across Canada. These programs are described in more detail below.

\subsubsection{ENGenuity}

ENGenuity began in 2003 as a weeklong introduction to engineering for girls at $\mathrm{QU}$. The program has since evolved into a weekend event for girls to learn about engineering. Activities within the weekend include: simulated mining exercise, which introduces mining and environmental engineering; flashlight creating, which introduces electrical engineering and design aspects; and creation stations, which introduces chemical engineering. These activities culminate into the final activity, a design project which is presented to parents at the final session of the weekend.

The program is guided by QU female engineering student volunteers who, over the course of a weekend, enlighten future female students about engineering and the vast array of career possibilities. The presence of current engineering students allows the girls to informally ask questions about university and engineering which in turn provides the engineering students with important mentoring opportunities. On the second day of the program, current female engineering professionals are invited to the event to have lunch with the girls. This portion gives the girls the opportunity to learn firsthand about what an engineering career may entail as well as the opportunity to meet an engineering graduate.

Since its inauguration year, ENGenuity has had continued success. Of the female students that participate in ENGenuity and subsequently attend QU, 46\% enter Applied Science at QU. However, only 7\% of all female students at QU are enrolled in Applied 
Science [27]. Although it is realized that these students may already have interest in engineering, the high percentage of those who choose engineering suggests that ENGenuity has a strong influence on female students when they are deciding their faculty at QU.

\subsubsection{Go ENG Girl}

Go ENG Girl has run in Ontario since 2005 at all universities that offer an engineering program. The program invites parents and girls in grades 7-10 to a morning workshop in order to learn about engineering. All guests start the day off listening to a female guest speaker, and then the girls and parents are split into separate groups. Girls in grades 7-8 do one engineering design activity, girls in grades 9-10 do a different activity, and the parents are invited to ask questions to a panel of female engineering students and professionals. All participants then meet for lunch where everyone is able to share what they did during the morning. This program is also run by female engineering student volunteers.

\subsubsection{Science Quest}

Science Quest, a summer camp promoting engineering and science, has been run at QU since 1988. Science Quest provides a variety of one week engineering and science related programs for students during their summer holidays. Although most of the programs are offered at QU, a separate arm offers a smaller number of similar camps to selected rural and remote communities. The camp provides instruction on general engineering concepts, computers and technology, as well as promoting girls in engineering. In addition to camps, during the end of the school year, Science Quest offers workshops to classrooms around the area to promote engineering and science to students. In 2008, it impacted 500 students from around Ontario.

A unique aspect of Science Quest, as well as other camps of similar nature run at other institutions, is that they are primarily student run with minimal input and support from the faculty and administration.

\section{Recommendations}

Although a variety of well established outreach programs exist at QU and other Canadian universities, the authors believe that dedication to outreach needs to be maintained and supported in the future. While outreach does impact thousands of students each year across the county, it is still a very small percentage of the entire K-12 student population. Outreach is also generally limited to students in the geographic areas in which these programs are run and, to those with sufficient financial resources and parental support.

Specifically in Canada, a course, workshop, or educational opportunity of some type should be developed to inform the current education graduates and teachers of what engineering is; how to integrate engineering concepts into their classroom; and resources for engineering lessons. The program should be well documented, supported, and developed to insure its effectiveness with both teachers and students.

\section{Conclusions}

Various activities which promote engineering as a whole, have the potential to increase the number of students currently enrolling in post-secondary engineering degrees. Several of these programs and activities have been through the foundation stage and are set to continue, however, additional efforts must be put in place to keep the programs running. These programs need to be further developed and analyzed for effectiveness.

\section{Acknowledgments}

The authors would like to acknowledge the financial support of The Natural Sciences and Engineering Research Council of Canada through their funding of the NSERC Chair in Design Engineering at Queen's University. They also wish to recognize the editorial support of Anne-Marie Pap.

\section{References}

[1] Board, N. S. (2003, August 14). "Science and Engineering Workforce Realizing America's Potential." Arlington, VA.

[2] Engineers, Canadian Council of Professional. "Canadian Engineers for Tomorrow: Trends in Engineering Enrolment from 2001-2005”. Ottawa : Canadian Council for Professional Engineers, 2006.

[3] Board, N. S. (2008). "Science and Engineering Indicators" 2008. Arlington, VA: National Science Foundation.

[4] Statistics, B. o. (2007, April 14). "Occupational Outlook Handbook, 2008-09 Edition, Teachers-Preschool, Kindergarten, Elementary, Middle, and Secondary." Retrieved October 24, 2008, from http://www.bls.gov/oco/ocos069.htm 
[5] Ingersoll, Richard. "Teaching Science in the 21st Century: The Science and Mathematics Teacher Shortage: Fact and Myth." National Science Teachers Association. [Online] April 30, 2007. [Cited: July 15, 2009.]

http://www.nsta.org/publications/news/story.aspx $? \mathrm{id}=53821$.

[6] National Center for Technological Literature, Musuem of Science Boston. "Engineering the Future Science, Technology, and the Design Process." Emeryville : Key Curriculum Press, 2008.

[7] Betz, J. A. (2004). "Design Competitions as Tools for a Change in Secondary (9-12) Technology Education: A Regional Case Study." American Society for Engineering Education Annual Conference and Exposition.

[8] Outreach, C. o. (2008). Frequently Asked Questions. Retrieved October 15, 2008, from PreK-12 Engineering: http://www.prek-12engineering.org/faq/

[9] Ory, J., \& Westrick, M. (2006). “An Internal Evaluation of the National Center for Engineering and Technology Education Professional Development Workshops." Chicago, IL: NCETE.

[10] Shumway, S., Berrett, J., Swapp, A. G., Erekson, T. L., \& Terry, R. E. A. "Successful Professional Developement Activity to Infuse Engineering Content for Utah 9-12 Teachers." American Society for Engineering Education.

[11] Krause, S., Burrows, V., Pizziconi, V., Culbertson, R., \& Carlson, M. (2006). "Project Pathways: Connecting Engineering Design to High School Science and Mathematics in a Mathematics-Science Partnership Program." American Society for Engineering Education.

[12] Engineer, P. (2008, November 23). Retrieved November 24, 2008, from Primary Engineer: http://www.primaryengineer.com/Index.htm

[13] Hotaling, L., McGrath, B., McKay, M., Shields, C., Lowes, S., Cunningham, C., et al. (2007)." Engineering Our Future New Jersey." American Society for Engineering Education.

[14] Zarske, M., Yowell, J., Sullivan, J., Knight, D., \& Wiant, D. (2007). The TEAMS Program: A Study of A Grades 3-12 Engineering Continuum. American Society for Engineering Education.

[15] Research, C. f. (2008). STOMP Network. Retrieved October 13, 2008, from Tufts University Center for Engineering Educational Research: http://www.stompnetwork.org/tufts

[16] EngQuest. (2008). EngQuest. Retrieved November 25, 2008, from EngQuest Students:

http://www.engineersaustralia.org.au/careers/engquest2008/students-entry.cfm
[17] Jeffers, A. T., Safferman, A. G., \& Safferman, S. I. (2004). Understanding K-12 Engineering Outreach Programs. Journal of professional issues in engineering education and practice , 95-108.

[18] Vanitchanant, N. (Summer 2008). Education is the Key to Success for Women. IEEE Women in Engineering, 1419.

[19] Societies, A. A. (2006). Data for Degrees. Retrieved October 24, 2008, from http://www.ewconline.org/data/degrees_data.asp

[20] Davis, R., \& Sullivan, K. (2007). Increase retention of women engineering students. American Society for Engineering Education.

[21] Schoenfeld, D. (2007). University of Utah College of Engineering Programs on Campus. Retrieved October 23, 2008, from University of Utah:

http://www.coe.utah.edu/k12/programs.php

[22] Zurn-Birkhimer, S. (2008). Purdue University Womengineers. Retrieved October 23, 2008, from Purdue University:https://engineering.purdue.edu/WIEP/Programs/P re-College $\% 20$ Students/EDGE/index.htm

[23] Life, E. Y. (2008). Why Engineering? Retrieved October 17, 2008, from Engineer Your Life:http://www.engineeryourlife.org/cms/6170.aspx

[24] Programs, Y. (2008). Explorations in Engineering. Retrieved October 23, 2008, from MichiganTech Summer Youth Program:

http://www.youthprograms.mtu.edu/eie/index.html

[25] Engineering, B. C. (2008). Bagley College of Engineering UFPME. Retrieved October 23, 2008, from Mississippi State University: http://www.bagley.msstate.edu/programs/outreach/ufpme/in dex.php

[26] Higgins, M. (2008, November 24). What do Education Students Learn about Engineering. (M. Spencer, Interviewer)

[27] Planning, O. o. (2008, November 4). CUDO. Retrieved November 26, 2008, from Public Accountability: http://www.queensu.ca/irp/accountability/cudo_08/SectionA .htm 